Conference abstract POT06

\title{
Modern Dressings for Wound Healing
}

\author{
R. RošIC, J. KRISTL, S. BAUMgaRTNER
}

Faculty of pharmacy, University of Ljubljana, Ljubljana, Slovenia

E-mail: romana.rosic@ffa.uni-lj.si (R. Rošic)

Sci Pharm. 2010; 78: 721

doi:10.3797/scipharm.cespt.8.POT06

Aim: Wound healing is a complex process with many potential factors that can delay healing. Imbalance between tissue deposition stimulated by growth factors and tissue destruction mediated by proteases causes nonhealing of chronic wounds [1]. To overcome the destroyable effect of proteases, the application of growth factors or protease's inhibitors has been shown as successful. The aim of our research work is to formulate and charaterize the biocompatible modern wound dressings with model protein for protease's inhibitor, which would enable protein stability, delivery and controlled release.

Materials and methods: Hydrogels of hydroxyethylcellulose (HEC) and polyvinyl alcohol (PVA) were made at different $\mathrm{m} / \mathrm{m}$ ratios and their rheological behaviors were performed by rotational viscosimeter (Rheolab MC 100, Physica). For HEC effects of sterilization process and osmolarity of the medium and for PVA effects of freeze-thaw cycles were evaluated. Egg albumin as model protein was incorporated into the hydrogels and drug release studies were performed by developed chamber simulating conditions at wound place. To increase protein stability hydrogels were lyophilized and tested for rehydration ability, viscosity and protein release. Electrospinning, which is a nanofiber-forming process where polymer solution or melt is charged to high voltages, was used for producing nanofibers from the same polymers.

Results and discussion: HEC hydrogel at 3w/w \% has appropriate rheologic properties, regardless of the medium used (water, phosphate buffer) or sterilization process performed. Strenght and rigidity of PVA hydrogels increases with number of freeze/thaw cycles. Mild process conditions enable homogenous incorporation of protein compound into HEC and PVA hydrogel without deteoriation of its native structure. The release of protein is in accordance with Fick's diffusion. Freeze-dryed HEC hydrogels were spontaneously rehydrated in 24 hours. Viscosity and thixothropy of rehydrated samples were reestablished and neither lyophilization nor freezing mode affects the protein structure or releases kinetics. Additionaly some data about nanofibers obtained by electrospinning will be presented. The nanofibers potentially mimic many roles of extracellular matrix to promote tissue growth.

Conclusion: Hydrogels with incorporated drugs that actively interfere in healing process and nanofibers with their unique properties represent improvement for treatment of chronic wounds.

[1] Enoch S, Leaper DJ. Basic science of wound healing. Surgery. 2005; 23; 2: 37-42. doi:10.1383/surg.23.2.37.60352 